\section{GEO}

Geograficando

ISSN: 2346-898X

geograficando@fahce.unlp.edu.ar

Universidad Nacional de La Plata

Argentina

\title{
Legalmente indígena: apuntes para pensar la alteridad santafesina desde una perspectiva multiescalar
}

\author{
Cabre, Pilar Guadalupe \\ Legalmente indígena: apuntes para pensar la alteridad santafesina desde una perspectiva multiescalar \\ Geograficando, vol. 16, núm. 1, 2020 \\ Universidad Nacional de La Plata, Argentina \\ DOI: https://doi.org/10.24215/2346898Xe063
}

Atribución no comercial compartir igual (CC BY-NC-SA) 4.0 


\section{Legalmente indígena: apuntes para pensar la alteridad santafesina desde una perspectiva multiescalar}

Legally indigenous: some notes on Santa Fe otherness from a multi-scale perspective

Pilar Guadalupe Cabre

DOI: https://doi.org/10.24215/2346898Xe063

Facultad de Humanidades y Ciencias, Universidad

Nacional del Litoral, Argentina

pilargcabre@hotmail.com

Recepción: 29 Diciembre 2019

Aprobación: 17 Marzo 2020

Recepción: 29 Diciembre 2019

Aprobación: 17 Marzo 2020

\section{Resumen:}

El objetivo del presente artículo es analizar los marcos legales vigentes que contribuyen a la conformación de la alteridad santafesina teniendo en cuenta la escalaridad de dicho proceso. La metodología utilizada es cualitativa a partir del análisis de contenido de las leyes y el uso de entrevistas personales semiestructuradas. El análisis escalar se presenta como primordial para entender las contradicciones que la legalidad presenta cuando se superponen diferentes marcos legales (provinciales y nacionales) generando confusión en las comunidades, y denotándose contradicciones en la forma en que se piensa el sujeto indígena "desde arriba". Este trabajo es un aporte al campo de la geografía en Santa Fe referida a la temática indígena, sobre todo a las geografías que buscan pensar "otras" territorialidades.

Palabras Clave: Pueblos originarios, Santa Fe, Indio permitido, Ley.

\section{AbStraCt:}

In this paper, the aim will be to analyze current legal frameworks that help conform Santa Fe otherness, bearing in mind the scalarity of the process. The methodology is qualitative, from an analysis of the laws and the use of semi-structured personal interviews. Scale analysis is essential to understand the contradictions posed by legality when different (provincial and national) legal frameworks overlap, generating confusion in the communities, and highlighting contradictions in a top-down vision of the indigenous subject. This paper contributes to the field of geography in Santa $\mathrm{Fe}$ in the area of indigenous issues, especially geographies that attempt to think about other territorialities.

KEYWORDS: Indigenous peoples, Santa Fe, Indio permitido/allowed Indian, Law.

\section{INTRODUCCIÓN}

La presente propuesta de trabajo busca dar cuenta de la relación existente entre ciertas narrativas escalares y la emergencia en el plano internacional de políticas del indigenismo. Permite mostrar cómo políticas de escala global legitimadas por discursos multiculturales hegemónicos repercuten en escalas nacionales y subnacionales. En este sentido, a partir de hacer hincapié en un caso particular (provincia de Santa Fe), busca analizar cómo se crea, reproduce y legitima el discurso acerca de lo que implica ser indígena a partir de lo que Briones (2005) identifica como "formación provincial de la alteridad". Para el abordaje de este eje temático proponemos analizar el marco legal vigente y algunas de las principales políticas públicas que de este devienen ${ }^{1}$.

Consideramos que la aplicación de ciertas políticas indigenistas debe entenderse dentro de un plano global que las articula, impulsa e implementa, y es por ello que la dimensión escalar aparecerá en el trabajo como eje articulador. Sin embargo, como sostiene Swyngedouwn (2010), intentaremos que el enfoque escalar sea dinámico por lo que evitaremos partir de una escala determinada, para enfocarnos en la multiescalaridad que atraviesa los procesos. 
Este texto se articula en dos grandes ejes; el primero intentará dar cuenta del marco teórico general tejiendo posibles conexiones entre conceptos tales como narrativas escalares (González, 2010), formaciones provinciales de alteridad (Briones, 2005) e “indio permitido" (Hale, 2004). El segundo ahondará en la construcción de la alteridad santafesina desde los marcos legales vigentes.

\section{Aspectos metodológicos}

La metodología utilizada para la realización de este trabajo es netamente cualitativa. Los datos empíricos con los que se trabajan devienen de la realización del análisis de contenido (López Noguero, 2002) de los textos que componen el corpus legal referido al indigenismo tanto en la provincia de Santa Fe como en nación. De los mismos fue clave observar: año de sanción, institucionalidad que "les otorga" a las comunidades originarias y requisitos exigidos para "comprobar" indeaneidad".

A su vez, para la investigación fueron preponderantes las entrevistas personales semiestructuradas (Archenti et.al., 2007) realizadas a miembros de organismos estatales de la provincia de Santa Fe, entre ellos, el Instituto Provincial del Aborigen Santafesino (I.P.A.S) y el Registro Especial de Comunidades Aborígenes (R.E.C.A.).

El trabajo se realiza teniendo en cuenta leyes y reglamentaciones previas al año 2016. La selección de dicho período corresponde a que el análisis con fuentes posteriores aún no se encuentra finalizado.

\section{RESULTADOS Y DiscusioneS}

\section{Debates en torno al concepto de escala}

La producción académica reciente vinculada a debates sobre el concepto de escalas (Moore, 2008; Escobar, 2007) intenta dar cuenta del mito que sostiene la desaparición de las mismas debido a procesos como el incremento de flujos globales vinculados a telecomunicaciones y desarrollo tecnológico. Desde la posición que deseamos adoptar aquí se busca incorporar una noción de escala que rompa con formas estáticas de pensar los procesos, sin caer en metáforas como las de muñecas rusas o escaleras. Por ello, abordaremos la escala desde un enfoque que se aleje de la noción jerárquica y piramidal para pensar en términos de ontologías planas (Escobar, 2006).

Como sostiene González (2010), traspasar el enfoque estático y jerárquico implica pensar las escalas desde la contingencia, para poder preguntarnos por qué determinado proceso sociohistórico sucede en un determinado espacio y qué luchas de poder confluyen en el mismo. En este sentido, Swyngedouwn sostiene que las escalas pueden considerarse "la materialización de las relaciones sociales de empoderamiento y de desempoderamiento, y la arena en la cual -y a través de la cual-operan” (Swyngedouwn,1997:169)

Retomamos aquí los aportes de De Landa (en Escobar, 2006), quien propone un análisis que parte del concepto de "ontologías planas" y se aleja de la dicotomía "micro" y "macro" para incorporar nociones de redes y ensamblajes. En este sentido, los ensamblajes se definen como totalidades con propiedades resultantes de la interacción constante de las partes. Estas entidades pueden componer redes por ejemplo de ciudades, estados y naciones, y evitar así el carácter cerrado de las categorías abriendo la posibilidad a la incorporación de diferentes elementos en constante movimiento.

Las ontologías planas contribuyen al debate que propone el presente artículo, ya que se presentan como una propuesta que rompe con la lógica de la modernidad y ayuda a repensar la colonialidad.

Los entes sociales existen en una amplia gama de escalas, lo cual hace mucho más compleja la situación que con las nociones convencionales de escalas (Escobar, 2007); las redes interpersonales pueden dar lugar a ensamblajes más amplios, como las coaliciones de las comunidades que forman la estructura de muchos movimientos de justicia social. Estos elementos 
permitirían construir mundos y conocimientos más allá del euro/logo-centrismo de las formas dominantes de modernidad (Aichino et al., 2013, p. 9).

Como hemos anticipado, la propuesta de trabajo contempla el cruce con diferentes escalas, entendidas desde la noción de ensamblaje, y busca condensar las relaciones entre diferentes partes de un todo vinculado a la formación de alteridades provinciales en Argentina haciendo foco en Santa Fe.

Creemos necesario pensar el indigenismo desde la escalaridad, porque podemos evidenciar correlatos entre las diferentes esferas que nos llevan a pensar cómo actúan las lógicas globales sobre prácticas locales y, a su vez, cómo prácticas locales resisten a lógicas globales. En este sentido, tal como sostiene Briones (2005), los límites administrativos del estado tanto provincial como nacional, aunque invisibles, se materializan a través de las políticas y marcos legales vinculados a la temática indígena. Estas esferas de decisión política entran en tensión con otras instancias y otras escalas, lo que da cuenta de procesos complejos que repercuten en la subjetivación indígena ${ }^{3}$.

Entendemos entonces que los límites provinciales generan representaciones localizadas de alteridad, lo que Briones denomina "formaciones provinciales de alteridad" . Esto permite, por ejemplo, que un mismo pueblo -según la provincia- genere diferentes formas de organización y canalización de demandas en función de cómo se habilitan o son ganados espacios a partir de las negociaciones etnopolíticas que llevan a cabo. Esta noción desanda el mito sobre los pueblos originarios como sujetos que persiguen y luchan por los mismos intereses, tal y como se los piensa desde el plano político legal. Además de ello, rompe con el velo homogeneizador de la diversidad promulgada por el estado y las narrativas multiculturales de la globalización.

En los apartados siguientes visualizamos la forma en que las diferentes esferas han pensado y resignificado el ser "indígena" desde una noción hegemónica, para dejar abierto el debate sobre cómo se autorreconocen y qué estrategias adoptan los sujetos indígenas.

\section{La receta universal para ser indígena}

En los últimos años, en especial a partir de la década de los 70, los estados-nación latinoamericanos han adoptado políticas vinculadas a la protección y reconocimiento de los pueblos originarios que los habitan. Dichas medidas no se encuentran aisladas del panorama internacional, ya que desde diferentes organismos, como por ejemplo las Naciones Unidas, se impulsaron propuestas de inclusión de la "diversidad" de las medidas adoptadas por los gobiernos neoliberales de turno, y luego retomadas o reconfiguradas por gobiernos de corte progresista, se vincularon a apoyar y promover el multiculturalismo. Sin embargo, dichas propuestas se han hecho bajo una lógica que exige a las comunidades un tipo específico de sujeto de derecho que Hale (2004) ha denominado "indio permitido". El "indio permitido" es un "indio bueno" que negocia diplomáticamente en los espacios que le son otorgados, que cumple con ciertas "pautas culturales" impuestas de manera hegemónica y forma parte de los mecanismos por los cuales los gobiernos hacen uso de derechos culturales para la neutralización de reclamos y luchas ${ }^{7}$.

A tono con estos discursos, pero desde el análisis escalar, Moore (2008) afirma que a partir de los años 70 hemos estado evidenciando junto con el incremento de discursos vinculados a políticas ambientales, de la diversidad sexual y movimientos indigenistas, resignificaciones en el concepto de escala. Estas resignificaciones derivan precisamente de la incorporación de dicha noción en las políticas globales. 


\section{Indigenismo de Necesidad de Urgencia8}

Vázquez (2012) nos acerca un análisis sobre la implementación de narrativas neoindigenistas a nivel sudamericano, que tiene en cuenta las particularidades otorgadas por cada estado-nación en la conformación de las agendas políticas ${ }^{9}$. Focalizaremos aquí en los aspectos relacionados al caso argentino.

La aplicación de políticas vinculadas a la creación de organismos de gobierno para la defensa de los derechos de los pueblos originarios se caracterizó por no generar grandes cambios sustanciales. A decir verdad, los miembros de pueblos originarios se han beneficiado de las políticas vinculadas a poblaciones vulnerables más que de aquellas que los han dispuesto como beneficiarios exclusivos. En palabras de Vázquez:

En términos genéricos, no se produjeron cambios sustanciales en las políticas del Gobierno Nacional y de los respectivos gobiernos provinciales y municipales con relación a los pueblos originarios. Es cierto que estos se beneficiaron con medidas inclusivas y de profundo impacto social tales como la asignación universal por hijo implementada en octubre de 2009, que alcanzó a 1 millón 927 familias, extendida, más tarde, a las mujeres embarazadas. Medidas de fuertísimo impacto social y que implicó una reducción de alrededor del $45 \%$ en el índice de la pobreza. Además, la ampliación del empleo, que permitió que unas 66 mil familias bajaran del Plan de Asignación Universal benefició también, aunque muy indirectamente, a la población indígena (Vázquez, 2012, p. 107).

A continuación, luego de haber desplegado ya un panorama general, nos centraremos en las regulaciones jurídicas de la Argentina en materia indígena para poder pensar así la construcción de las escalas desde lógicas de poder y de las narrativas escalares como justificativos de dichas lógicas.

\section{Los esquemas de la ley. El sujeto indígena en el panorama nacional}

En lo que respecta al marco legal argentino en materia de comunidades originarias se deben de resaltar como ejes principales de acción la Constitución $\mathrm{Nacional}^{10}$ y el convenio $\mathrm{N}^{\circ} 169$ de la Organización Internacional del Trabajo (OIT).

La ley No 24.071 (B.O. 1992) ratifica en sus artículos 13, 14 y 15 lo estipulado en el convenio $\mathrm{N}^{\circ} 169$ de la OIT. Promulga el respeto hacia la relación de los pueblos con los territorios, garantiza y protege aquellos que las mismas ocupan tradicionalmente, junto con el otorgamiento de la posibilidad de administrar los recursos que en dichos territorios se hallaren. Cabe aclarar que el primer convenio respectivo a derechos de comunidades originarias es el $\mathrm{N}^{\circ} 107$ (1957), ratificado en Argentina en 1960. El mismo se toma como antecedente al $\mathrm{N}^{\circ} 169$ a pesar de su enfoque asimilacionista, ya que, según Juan Manuel Salgado (Kosovsky e Ivanoff, 2015), se daba a entender que las comunidades irían "disolviéndose" en contacto con las "sociedades modernas".

Nos centraremos de aquí en adelante en dos leyes que a los fines de este trabajo competen y se encuentran en relación directa con las de nuestra provincia de Santa Fe para llevar a cabo sanciones y acciones en lo que respecta a comunidades originarias. Las leyes que se tratarán son la ley nacional $N^{\circ} 23.302$ (1985) y la No 26.160 (2006).

La ley No 23.302, sancionada en el año 1985, reconoce la personería jurídica a las comunidades residentes en el país. La misma se adquiere a partir del registro y se les permite a la vez su posterior cancelación en caso de que así se lo deseare. En este sentido, debe de destacarse la ausencia de la idea de comunidades como preexistentes al estado, ya que se supone que las mismas existen a través del registro y desaparecen a través de la cancelación de la inscripción.

Por otro lado, la misma ley es la que sanciona a través del artículo 6 la creación del Instituto Nacional del Indígena (INAI), el cual se encargará principalmente del registro de comunidades. Para el ejercicio de dicha competencia, el INAI ha creado el Registro de Comunidades Indígenas (RE. NA. CI), reglamentado por la resolución 4811/96. 
Algunos autores, como Bidaseca, Gigena, Guerrero, Millan y Quintana (2008), identifican la personería jurídica como un proceso que contribuye al empadronamiento y "conteo" de los pueblos originarios, sujeto a formalismos jurídicos que se presentan como novedosos pero que reproducen lógicas del colonialismo, al proponer inventariar diferencias culturales como datos clasificables y censables, "porque justamente el gran relato del Estado-nación se funda sobre la represión de las comunidades singulares, de sus identidades" 11 (Bidaseca et al., 2008, p. 7). En este artículo consideramos, luego del análisis de los textos legales y de una indagación en campo a través de entrevistas en organismos públicos, que esto es efectivamente así en la provincia de Santa Fe.

En lo que respecta a la ley No 26.160, "ley de emergencia en materia de posesión y propiedad de las tierras" (2006), con reglamentación por decreto nacional 1122/2007, la misma estipula el cese de desalojos y desplazamientos forzados de Comunidades Originarias de sus lugares de residencia, e impulsa a la vez un Relevamiento Territorial de Comunidades Indígenas (RE.TE.CI) con el fin de realizar un mapeo de los asentamientos de las Comunidades del país, con la idea a posteriori de que las tierras que ocupan se conviertan efectivamente en propiedad de las comunidades. Al cumplirse el período estipulado para la finalización del mismo, y luego de considerarse la imposibilidad de concretarlo en todo el país, se sancionó la ley No 26.554 (2009), que promovía la continuidad de los relevamientos hasta el año 2013.

Entre las actividades a realizar mediante el RE.TE.CI se encontraban: identificación de las comunidades indígenas, relevamiento social de la organización comunitaria, relevamiento técnico, jurídico y catastral del territorio comunitario, relevamiento socioproductivo y recursos naturales.

Cañuqueo (2015), en referencia al territorio relevado en Rio Negro por la ley nacional $\mathrm{N}^{\circ} 26.160$, analiza las dificultades presentadas debido, por ejemplo, a la no inclusión de territorios de despojo histórico en la cartografía relevada como lo proponían las comunidades; invisibilizaba las dificultades y la conflictividad en la ocupación, y reproducía un discurso de un sujeto indígena que no entraba en contradicción con los marcos regulatorios. Esta forma de cartografiar no solo se vincula con la forma de control estatal expuesta por Bidaseca et al. (2008), sino que además niega la posibilidad de incorporar otras voces a la cartografía, que no sean las hegemónicas; en cambio, sí se reprodujeron, aunque de manera sutil, lógicas propias de la negación como las de la campaña al desierto.

\section{La formación de la alteridad provincial santafesina. Análisis de marcos legales vigentes}

En este apartado proponemos acercar las leyes correspondientes al ámbito provincial de Santa Fe. Consideramos que analizarlas a la luz del marco teórico propuesto permite repensar cómo se construye desde arriba un sujeto indígena específico. Entendemos que al realizar el recorte temático y focalizarnos solo en los marcos legales estamos poniendo el foco en los grupos hegemónicos y dejando para otra instancia de investigación lo que sucede con los grupos que resisten, reciben, se amoldan o rechazan dichas propuestas.

Desde el plano jurídico, la provincia de Santa Fe reconoce los derechos de las Comunidades Aborígenes a partir de dos leyes básicas: ley $\mathrm{N}^{\circ} 11.078$ y ley $\mathrm{N}^{\circ} 12.086$.

La ley provincial $\mathrm{N}^{\circ} 11.078$ define las comunidades aborígenes como:

el conjunto de personas que se reconozcan como tales con identidad, cultura y organización propia, conserven normas y valores de su tradición y hablen o hayan hablado una lengua propia y tengan un pasado histórico común, sea que convivan nucleados o dispersos, en zonas rurales o urbanas.

En este sentido se destaca el término urbanas porque se encuentra presente en la ley provincial, y no en las leyes nacionales. En las reformas planteadas en el Código Civil y de Comercio en el año 2012, el texto redactado por el Poder Ejecutivo afirmaba que "la propiedad comunitaria es el derecho real que recae sobre un inmueble rural", y se dejaba de lado a aquellas comunidades que habitaban en ciudades. Ante la imposibilidad de concretarse un acuerdo en materia de qué se define como propiedad comunitaria de la tierra, el Código 
Civil y Comercial 2015 aclara el futuro tratamiento de un apartado especial en lo que a este tema respecta, junto con la posibilidad de entrega de tierras a través de dicha forma jurídica.

\section{Reconocimiento jurídico de las comunidades originarias (ley 11.078)}

La ley provincial $\mathrm{N}^{\circ} 11.078$ se sancionó en el año 1993 (B. O. 1994), sin embargo, su artículo $\mathrm{N}^{\circ} 7$ fue reglamentado en el año 2009 a través del decreto $\mathrm{N}^{\circ} 1175$. Y en 2012 recibe otra modificación a través del decreto $\mathrm{N}^{\circ} 2325$, que permite un cambio en el órgano estatal de dependencia del Registro Especial de Comunidades Aborígenes.

En términos generales la ley $\mathrm{N}^{\circ} 11.078$ reconoce, en consonancia con el artículo 75 inciso 17 de la Constitución Nacional y el Convenio 169 de la Organización Internacional del Trabajo(OIT), ratificado en Argentina por la ley 24.071, la preexistencia de las comunidades a los estados nacionales, por ende, reconoce a las mismas la personería jurídica de derecho público, a los términos del artículo 33 del Código Civil y de Comercio (C. C. C.). Se define según el Código Civil y Comercial como persona jurídica de derecho público: el estado nacional, las provincias, la ciudad Autónoma de Buenos Aires, los municipios, las entidades autárquicas y demás organizaciones constituidas en la república a las que el ordenamiento jurídico atribuyere dicho carácter. A su vez, la ley gestiona la creación de un órgano de inscripción provincial, el Registro Especial de Comunidades Aborígenes (R. E. C. A.). A la vez, regula las relaciones de las comunidades entre sí y con el resto de la sociedad santafesina, reconociendo sus culturas y promoviendo la inserción social de las mismas.

Previo al decreto $\mathrm{N}^{\circ} 1175$, la ley en su artículo 7 afirmaba que las comunidades podrían inscribirse como asociaciones civiles, pero ante las modificaciones aportadas por dicho decreto, se las exime de la personería jurídica privada y se les otorga la pública, en un intento más de concebirlas como previas a la conformación del estado nacional y con prácticas de vida que exceden, por su origen, la ley occidental.

Los artículos $\mathrm{N}^{\circ} 8$ a 14 de dicha ley especifican la creación de una autoridad de aplicación, denominada Instituto Provincial del Aborigen Santafesino (IPAS). El mismo está constituido por un presidente, designado por el Poder Ejecutivo, y un consejo integrado por 5 representantes de comunidades aborígenes. Se lo dispone además como órgano consultivo y de asesoramiento a la Organización de Comunidades Aborígenes de Santa Fe (OCASTAFE). Si bien la ley por la cual se gesta el IPAS es del año 1993, recién en el año 2005 se reglamentó el artículo de creación de dicho organismo (decreto 2204/2005) y entró en funcionamiento en el año 2009. El mismo en 2011 pasó a ser un órgano dependiente del Ministerio de Seguridad y Desarrollo Social.

El antecedente institucional del IPAS fue la Dirección General del Aborigen, creada a partir de la ley provincial $N^{\circ} 5487$ del año 1961 (B. O. enero de 1962). La misma dependía del Ministerio de Agricultura y Ganadería de la Provincia, fundado con objetivos de radicar los núcleos aborígenes en la provincia. A diferencia del IPAS, la Dirección General del Aborigen estaba conformada por un presidente, que era el ministro de Agricultura y Ganadería de la provincia o un funcionario designado por él, y cuatro vocales con carácter ad honorem, con preferencia vecinos o personas vinculadas a los mayores núcleos de indígenas existentes en el territorio de la provincia. A la vez, tal como se afirma en el texto de ley:

La Dirección Provincial del Aborigen creará colonias agrícola-ganaderas, forestales para indígenas unión del aborigen a la vida rural. A tal efecto la Provincia dispondrá la cesión a la Dirección Provincial del Aborigen de las tierras fiscales necesarias más aptas y previo dictamen de los organismos técnicos dependientes del Ministerio de Agricultura y Ganadería. Transcurridos diez años de funcionamiento de la colonia el Poder Ejecutivo procederá a transferir el dominio de los distintos lotes a los pobladores, los que no podrán enajenarlos por el término de treinta años (Art. 3).

Como puede observarse, dicha ley asumía explícitamente la existencia de comunidades indígenas solo en zonas rurales, por ende, su vigencia no solo quedaría obsoleta ante los procesos venideros, y sobre todo ante la presencia de comunidades aborígenes en la ciudad (Maidana y Tamagno, 2011), sino que también -al no 
ser miembros de comunidades aborígenes quienes componían la Dirección- se reducía la participación de las comunidades en las tomas de decisiones de los territorios sobre los que se asentaban y asientan. A la vez, se observa un intento en el reconocimiento de la posesión de tierras pero con plazos para la posible enajenación incluso para la obtención de las mismas-, ya que se estipula una residencia mínima de diez años sobre los lotes para obtener su título de propiedad. En este sentido, debemos agregar que como la sanción de la les es previa a la reforma constitucional de 1994, el reconocimiento de las comunidades originarias como preexistentes al estado nación aún no era parte de los proyectos políticos del país.

Como parte de la reglamentación del artículo $\mathrm{N}^{\circ} 7$ de la 11.078 se crea el Registro Especial de Comunidades Aborígenes (R. E. C. A.), el cual en primera instancia funcionó como dependencia del Ministerio de Desarrollo Social de la Provincia de Santa Fe en la Dirección de Provincial de Pueblos Originarios y Equidad, para luego ser transferido al Ministerio de Justicia y Derechos Humanos de la Provincia de Santa Fe en la Dirección Provincial de Registros. Tanto el R. E. C. A como el I. P. A. S. actúan en conjunto en lo que respecta al reconocimiento y entrega de escrituras a las comunidades de la provincia.

\section{Una ley de propiedad comunitaria (ley 12.086)}

El estado provincial garantiza a través de la ley $\mathrm{N}^{\circ} 12.086$ (2002) la entrega y reconocimiento de territorios a las comunidades originarias a partir de la adjudicación de lotes fiscales y parcelas de islas, pero se hace mención especial en dos anexos a cuáles son las parcelas específicas a reconocer. Esto quiere decir que para muchas comunidades la ocupación está siendo de hecho.

Las comunidades registradas tienen el reconocimiento de su propiedad comunitaria; las pueden inscribir a su nombre y tanto la posesión como la propiedad de sus tierras resultan inembargables, imprescriptibles, inajenables, y libres de impuestos en el Registro General de la Propiedad y Catastro de la Provincia de Santa Fe.

Hasta el momento se han especificado dos leyes provinciales, la $\mathrm{N}^{\circ} 12.086$ y la $\mathrm{N}^{\circ} 11.078$; a continuación se explicitará la ley 11.078 - por ser aquella de la cual surgen los organismos actuales de regulación-, y su antecesora, la ley provincial $\mathrm{N}^{\circ} 10.375$ del año 1989.

Figura 1: Marco legal e institucional

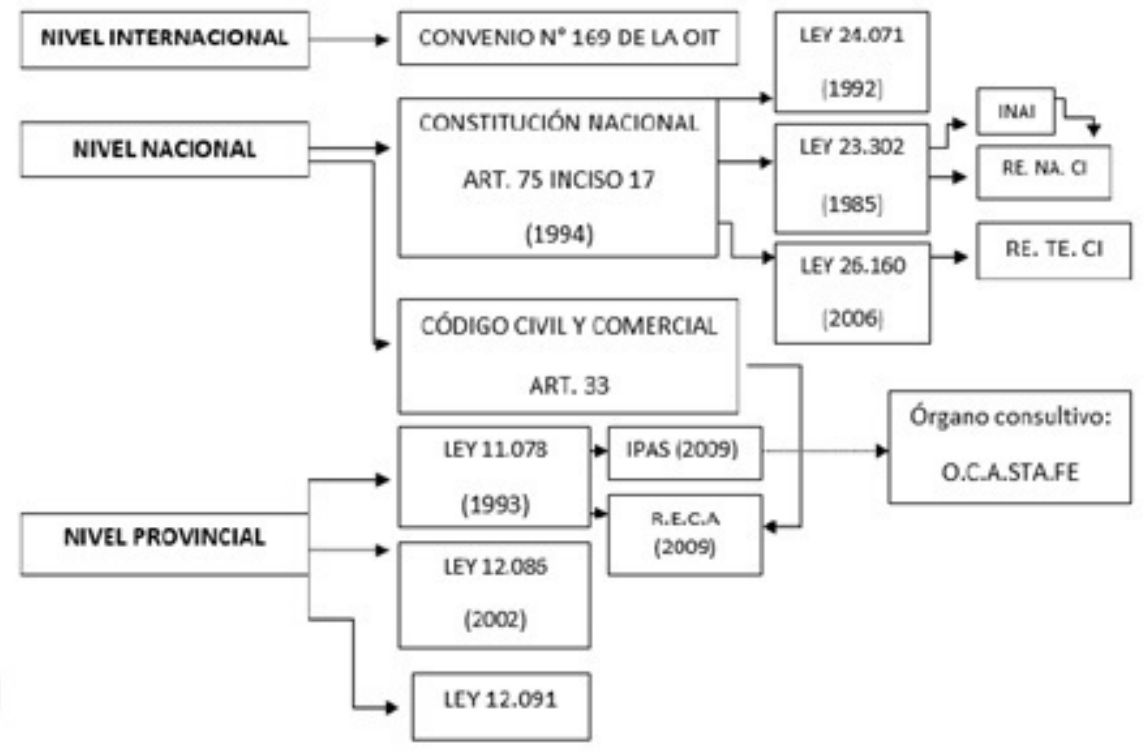

Fuente: Cabre (2019) 


\section{Lo nacional y lo provincial en disputa: puntos de reflexión en torno a los marcos legales vigentes}

El presente apartado es una reflexión acerca de las contradicciones entre los marcos legales existentes, que deja entrever las dificultades de la ley para pensar y reflexionar sobre el sujeto indígena. Por otro lado, permite pensar la complejidad de los procesos de empoderamiento y desempoderamiento de los que forman parte. Incluso, a partir del concepto de escala, se puede pensar cómo se superponen conflictos y miradas en el ejercicio de lógicas dominantes, que alimentan el ensamblaje y complejizan los entramados escalares, los cuales durante mucho tiempo fueron pensados desde la verticalidad. A continuación se exponen los principales aspectos de la tensión entre dos escalas: la nacional y la provincial.

A nivel nacional, en las reformas del nuevo Código Civil y de Comercio, se hizo necesario estipular de algún modo e incluir la propiedad comunitaria de la tierra; sin embargo, lo propuesto ha sido pensar a futuro un apartado específico sobre la propiedad comunitaria. Por su parte, el estado provincial, como hemos visto, presenta una ley específica que aborda la temática y garantiza, aunque con ciertas limitaciones, el acceso a la propiedad comunitaria de las comunidades originarias.

Durante el Encuentro Nacional de Organizaciones Territoriales de Pueblos Originarios (ENOTPO), del cual participó OCASTAFE, realizado en el mes de julio de 2015, el presidente del INAI, Daniel Fernández, planteó:

a partir de agosto comienza a regir el Nuevo Código Civil. En el Código Civil de Vélez Sarsfield omitió a los Pueblos Originarios y a la propiedad comunitaria. El código civil rige para todo el país y para todas las provincias, y esto es lo importante. El Nuevo Código dice que se va a hacer una ley que va a instrumentalizar la propiedad comunitaria indígena. Y esta Ley va a ser parte del código civil, por lo que deberá ser aplicado en todas las provincias (ENOTPO, 2015:4).

Entre las principales observaciones que desde la provincia de Santa Fe se le han hecho al anteproyecto de ley propiedad comunitaria indígena (título I, "Propiedad comunitaria de la tierra") resulta de notable importancia la siguiente:

nos parece que resulta fundamental que quede claramente diferenciado el reconocimiento de las comunidades aborígenes a través de su personería jurídica como sujeto de derecho público; de las acciones de reparación histórica emprendidas por el Estado (en el caso, restitución de tierras) y la regulación de la propiedad comunitaria indígena como un derecho real autónomo. Entendemos que la ley no distingue claramente las tres cuestiones sin perjuicio de reiterar nuestro reconocimiento de que implica un avance.

A modo de ejemplo, una comunidad puede estar reconocida en su personería pero no poseer tierras en propiedad comunitaria indígena. $\mathrm{O}$, también por hipótesis, una comunidad puede estar reconocida jurídicamente, haber recibido tierras como parte de una política de restitución, pero además, puede haber adquirido tierras o inmuebles con su giro económico y pretender someterlo al régimen de propiedad comunitaria indígena o preferir inscribir estos últimos inmuebles adquiridos por el régimen de propiedad privada regulado en el Código Civil (lo que no debería cercenarse (IPAS, 2015:3).

Por otro lado, se hace hincapié a nivel provincial en el concepto de la expresión: "La propiedad comunitaria indígena recae sobre las tierras que, en forma tradicional y pública, ocupan las comunidades". Dicho esto, especifican primero que con el término tradicional la ley debería estarse refiriendo a la ocupación que realizan sobre el territorio y las prácticas culturales que llevan a cabo sobre las mismas, descartándose en ocasiones la ancestral localización de la comunidad. Por otro lado, y en consonancia con el convenio 169 de la OIT y el artículo 75 inciso 17 de la $\mathrm{CN}$, las leyes provinciales buscan el reconocimiento de tierras "aptas y suficientes para el desarrollo humano", que no siempre se condicen con las que actualmente ocupan las comunidades.

Parece relevante destacar además que en lo que respecta al registro de las comunidades, se encuentran discrepancias a la hora de la inscripción de las mismas, ya que, en ocasiones, comunidades que no figuran inscriptas en el R. E. C. A. sí lo están en el RE. NA. CI. En este sentido, desde la provincia de Santa Fe se propone el camino inverso; las mismas se registran en el R.E.C.A y luego son elevados los informes de registro 
al RE. NA. CI., en primera instancia, porque es más factible y rápida la comprobación in situ por parte de los organismos provinciales que de los nacionales (entrevista personal, 2015).

En lo que respecta a la ley nacional $\mathrm{N}^{\circ} 26.160$, las organizaciones del ENOTPO mostraron su disconformidad porque el relevamiento no otorga la propiedad de la tierra. Desde el R. E. C. A. se afirma que esto ha generado confusión en ocasiones, ya que algunas comunidades reclamaban la propiedad de la tierra basándose en el hecho de haber sido relevadas por el RE. TE. CI. (entrevista personal, 2015).

\section{CONSIDERACIONES FINALES}

Durante el presente trabajo hemos recuperado aspectos centrales de la conformación en materia legal, de un sujeto indígena pensado y diagramado desde arriba. Sin embargo, este pensar "desde arriba" no implica una sola escala, sino que demuestra cómo se superponen y actúan diferentes esferas de poder y toma de decisiones sobre los mismos grupos.

Consideramos que la reconfiguración de sujetos indígenas en esferas nacionales y provinciales se acerca a la idea de "indio permitido". Un sujeto propuesto por discursos impartidos desde organismos internacionales que se replica de manera simultánea y a la vez con particularidades en las provincias constituyendo formas propias de pensar y "gestionar" la alteridad.

Así, en el debate hemos evidenciado que la escalaridad que solíamos concebir antes como jerárquica no es más que un ensamblaje en el que nación y provincia entran en tensión, en este caso, desde la óptica jurídica, trayendo a discusión que aquello considerado legítimo por ser "legal" puede convertirse en una dificultad para las comunidades en su día a día.

El presente trabajo se basó en un análisis de los marcos legales atinentes a la temática indígena, no obstante, entiende que es necesario pensar y trabajar las particularidades que atañen a la formación de alteridades locales a partir de un abordaje específico desde la percepción de cada una de las comunidades por dos motivos: primero, para desandar la idea de homogeneidad a la que muchas veces se alude cuando se habla de "pueblos originarios" como categoría. Segundo, porque "bajar la voz" (Zusman, 2014) es una forma más de abrir el juego a que "otros" discursos sean escuchados.

Por último, consideramos que un análisis de las regulaciones vigentes permite generar una consciencia crítica que abra el debate para empezar a pensar con las comunidades y para las comunidades, no sobre ellas.

\section{REFERENCIAS}

Aichino, L., Arancibia, L., Cisterna, C., Juliá, C., Llorens, S., Palladino, L., Pedrazzani, C., Ricci, C., y Robino, F. (2013). Políticas de lugar: convergencias de discusiones e intervenciones académicas sociales y políticas. Cardinalis, Revista del Departamento de Geografía de Córdoba, 1(1), 1-18. Recuperado de http://www.revistas.unc.edu.ar/ index.php/cardi/article/view/7064/8137

Archenti, N.; Marradi, A. y Piovanni, J. (2007). Metodología de las Ciencias Sociales. Buenos Aires: Emecé.

Bidaseca, K.; Gigena, A.; Guerrero, L.; Millan, F. y Quintana, M (2008). Dispositivos miméticos y efectos de identidades. Ensayo de una interpretación crítica sobre las personerías jurídicas y las comunidades originarias. Papeles de Trabajo. Revista electrónica del Instituto de Altos Estudios Sociales de la Universidad Nacional de General San Martín, 2(3). Recuperado de http://www.idaes.edu.ar/papelesdetrabajo/paginas/Documentos/03_Inform e_investigacion-Karina_Bidaseca.pdf

Briones, C. (Comp.) (2005). Cartografias Argentinas. Politicas indigenistas y formaciones provinciales de alteridad. Buenos Aires: Antropofagia.

Cabre, P. (2019) La ciudad y sus otros. Territorialidades periféricas en el Area Metropolitana de Santa Fe. Una aproximación a la Comunidad Qom Las Lomas (Tesina de grado). Universidad Nacional del Litoral, Santa Fe, Argentina. 
Pilar Guadalupe Cabre. Legalmente indígena: apuntes para pensar la alteridad santafesina desde una...

Cañuqueo, L. (2015). El territorio relevado, el territorio disputado. Apuntes sobre la implementación de Ley nacional 26.160 en Río Negro, Argentina. Revista de Geografia Norte Grande, 62, 11-28. http://dx.doi.org/10.4067/S0 718-34022015000300002

Constitución Nacional Argentina. (2005). Corte Suprema de Justicia de la Nación. Buenos Aires: Ed. La Ley.

Encuentro Nacional de Organizaciones Territoriales de Pueblos Originarios (2015). El territorio es vida y la vida es irrenunciable. Marcos de discusión para la plurinacionalidad: territorio-identidad-autonomía. Recuperado de htt p://www.enotpo.blogspot.com/2015/07/el-territorio-es-vida-y-la-vida-es.html

Equipo Nacional de Pastoral Aborigen. (2011). Advertencia sobre la inejecución de las leyes nacionales $N^{\circ} 26.160$ y 26.554. Recuperado de http://www.redaf.org.ar/wp-content/uploads/2011/05/INFORME-LEY-26160.pdf

Equipo Nacional de Pastoral Aborigen. (2013). Nueva advertencia sobre la inejecución de la ley 26.160. Recuperado de http://www.sogip.files.wordpress.com/2013/08/ici.pdf

Escobar, A. (2007). The "ontological turn" in social theory. A Commentary on "Human geography without scale", by Sallie Marston, John Paul Jones II and Keith Woodward. Transactions of the Institute of British Geographers, 32(1), 106-111. https://doi.org/10.1111/j.1475-5661.2007.00243.x

Gonzalez, S. (2010) Las narrativas escalares de la globalización. Neoliberalismo y ciudades competitivas. En C. Brandao y V. Fernández (Dir.), Escalas y politicas de desarrollo regional. Desafios para América Latina (pp. 123-149). Buenos Aires: Miño Dávila Editores.

Hale, C. (2004). El protagonismo indígena, las políticas estatales y el nuevo racismo en la época del indio permitido. Conferencia Construyendo la paz: Guatemala desde un enfoque comparado (pp. 51-66). Guatemala: Fundación Propaz.

Instituto Provincial del Aborigen Santafesino (2012). Posición del Instituto Provincial de Aborigenes Santafesinos con respecto a la introducción del concepto de propiedad comunitaria en la reforma del código civil. Recuperado de http://www.santafe.gov.ar/index.php/web/content/download/158780/777506/file/Ponencia\%20Asambl ea\%20Publica.pdf

Instituto Provincial del Aborigen Santafesino. (2015). Observaciones anteproyecto de ley de propiedad comunitaria.

Kosovsky, F. e Ivanoff, S. (Comp.) (2015) Dossier de propiedad comunitaria indigena. Comodoro Rivadavia: Universitaria de la Patagonia-EDUPA. Recuperado de http://www.edupa.unp.edu.ar/propiedad-comunitariaindigena

López Noguero, F. (2002) El análisis de contenido como método de investigación. XXI Revista de Educación, 4, 167-180. Recuperado de http://rabida.uhu.es/dspace/bitstream/handle/10272/1912/b15150434.pdf?sequen $\mathrm{ce}=1$

Ley 23.302.Ley sobre politica Indigena y apoyo a las comunidades aborigenes. Senado y Cámara de Diputados de la Nación Argentina. Buenos Aires, Argentina, 17 de Febrero de 1989.

Ley 24.071. Apruébase el Convenio 169 de la Organización Internacional del Trabajo sobre Pueblos Indígenas y Tribales en Países Independientes. Senado y Cámara de Diputados de la Nación Argentina. Buenos Aires, Argentina, 20 de abril de 1992.

Ley 12.086. Adjudicación de lotes y parcelas de islas fiscales a las Comunidades Aborígenes. Legislatura de la Provincia de Santa Fe. Santa Fe, Argentina, 3 de enero de 2002.

Ley 12.091. Legislatura de la Provincia de Santa Fe. Santa Fe, Argentina, 9 de diciembre de 2003.

Ley 11.078. Regula las relaciones colectivas e individuales de las comunidades aborigenes. Legislatura de la Provincia de Santa Fe. Santa Fe, Argentina, 22 de agosto de 2012.

Ley $N^{\circ}$ 26.160. Emergencia en materia de posesión y propiedad de las tierras. Senado y Cámara de Diputados de la Nación Argentina. Buenos Aires, Argentina, 1 de diciembre de 2006.

Maidana, C. y Tamagno, L. (2011). Grandes urbes y nuevas visibilidades de la diversidad. Revista Brasileña de Estudios Urbanos y Regionales, 13(1), 51-61. https://doi.org/10.22296/2317-1529.2011v13n1p51

Moore, A. (2008). Rethinking scale as a geographical category: from analysis to practice. Progress in Human Geography, 32(2), 203-225. https://doi.org/10.1177/0309132507087647 
Palladino, L. (2014) Esencialismo indígena y autenticidad en disputa. Análisis de la tramitación de la personería jurídica en la reivindicación de la comunidad comechingón del Pueblo la Toma (2008-2009). Revista Intersticios de la politica y la cultura, 3(5), 69-91. Recuperado de http://www.revistas.unc.edu.ar/index.php/intersticios/a rticle/view/7510/8684

Ramírez Velázquez, B. (2010). De la escala al espacio en la construcción del desarrollo regional. En C. Brandao y V. Fernández (Dir.), Escalas y politicas de desarrollo regional. Desafios para América Latina (pp. 217-237). Buenos Aires: Miño Dávila Editores.

Swyngedouw, E. (1997). Excluding the other: the contested production of a new "gestalt of scale", and the politics of marginalization. En E. Swyngedouw, R. Lee y J. Wills (Ed.), Geographies of Economies (pp. 167-177). London, Edward Arnold.

Swyngedouw, E. (2010). ¿Globalización o glocalización? Redes, territorios y reescalamiento. En C. Brandao y V. Fernández (Dir.), Escalas y políticas de desarrollo regional. Desafios para América Latina (pp. 47-76). Buenos Aires: Miño Dávila Editores.

Vázquez, H. (2012). Pueblos originarios, cuestión étnico nacional en el cono sur latinoamericano y sus contradicciones con los modelos neodesarrollistas propuestos por los gobiernos progresistas. Papeles de Trabajo, 23, 98-121. Recuperado de http://www.pdfs.semanticscholar.org/5e74/10b91eb1b66664f1086ca90807b6f7ccd03b.pdf

Zusman, P. (2014). La descripción en Geografía: un método, una trama. Boletin de Estudios Geográficos, 102, 135-149. Recuperado de http://www.bdigital.uncu.edu.ar/objetos_digitales/6811/007-zusman-beg-102.pdf

\section{Notas}

1 Creemos que en la construcción del sujeto indígena como sujeto de derecho intervienen otros discursos hegemónicos como textos escolares y publicaciones académicas que por cuestiones de recorte temático no se abordan aquí.

2 Otros autores como Palladino, L. (2014) han analizado los requisitos impuestos por el Estado a los miembros de las comunidades a la hora de la tramitación de la personería jurídica, exigiendo estos como documentos probatorios de su identidad.

3 A su vez, desde abajo se generan procesos inversos de negociación y resistencia, que por cuestiones de recorte temático no serán abordados aquí.

4 Las formaciones de alteridad no solo producen categorías y criterios de identificación/clasificación y pertenencia, sino que - a partir de la administración de jerarquizaciones socioculturales- regulan condiciones de existencia diferenciales para los distintos tipos de otros internos que se reconocen como parte histórica o reciente de la sociedad sobre la cual un determinado Estado-nación extiende su soberanía (Briones, 2005, p. 17)

5 Este tema es abordado en mi tesis de grado para el caso de la comunidad qom Las Lomas, en el Área Metropolitana de Santa Fe (Cabre, 2019).

6 El informe anual del PNUD sobre el desarrollo humano que, por primera vez en 2004, eligió la "diversidad" como tema central para acompañar el análisis estadístico de bienestar social y económico.

7 Hale sostiene "sería un grave error asumir que el aumento de presencia indígena en los pasillos del poder implica un incremento garantizado de posibilidades político para la población indígena en general” (Hale, 2004, p. 6).

8 Este concepto es utilizado por Claudia Briones retomando a Lorenzetti y Lenton, para definir "forma de gestión de la diversidad neoasistencialista, que se concentra en extender a la ciudadanía indígena políticas focalizadas de asistencia diseñadas para la ciudadanía en general, implicando a los "asistidos" en su propio auto-cuidado y responsabilizándolos en lo que hace a afrontar inusitados índices de pobreza e indigencia” (Briones, 2005:38).

9 "Pueblos originarios, cuestión étnico nacional en el cono sur latinoamericano y sus contradicciones con los modelos neodesarrollistas propuestos por los gobiernos progresistas".

10 La Constitución Nacional, a través de las reformas introducidas en el año 1994 propone en su artículo 75 inciso 17: "Reconocer la preexistencia étnica y cultural de los pueblos indígenas argentinos. Garantizar el respeto a su identidad y el derecho a una educación bilingüe e intercultural, reconocer la personería jurídica de sus comunidades, y la posesión y propiedad comunitaria de las tierras que tradicionalmente ocupan; y regular la entrega de otras aptas y suficientes para el desarrollo humano; ninguna de ellas será enajenable, transmisible ni susceptible de gravámenes o embargos. Asegurar su participación en la gestión referida a sus recursos naturales y a los demás intereses que los afecten. Las provincias pueden ejercer concurrentemente estas atribuciones". 
Pilar Guadalupe Cabre. Legalmente indígena: apuntes para pensar la alteridad santafesina desde una...

11 En estos términos, el diseño de lo que una comunidad originaria debe ser se condice con lo propuesto por Hale (2004) mencionado previamente. En este sentido: "El Estado hace patente el hecho de que el orden de las partes altera siempre el resultado" (Bidaseca, 2008, p. 8)

\section{BY-NC-SA}

